\title{
Psychosocial risk and protective factors associated with perpetration of gender-based violence in a community sample of men in rural KwaZulu-Natal, South Africa
}

\author{
N Mngoma, ${ }^{1,2} \mathrm{PhD} ; \mathbf{S}$ Fergus, ${ }^{1} \mathrm{PhD} ;$ A Jeeves, ${ }^{3} \mathrm{PhD} ; \mathbf{R}$ Jolly, ${ }^{1,4} \mathrm{PhD}$ \\ ${ }^{1}$ School of Kinesiology and Health Studies, Faculty of Arts and Science, Queen's University, Kingston, Ontario, Canada \\ ${ }^{2}$ School of Rehabilitation Therapy, Faculty of Health Sciences, Queen's University, Kingston, Ontario, Canada \\ ${ }^{3}$ Independent researcher, formerly Department of History, Faculty of Arts and Science, Queen's University, Kingston, Ontario, Canada \\ ${ }^{4}$ Departments of Comparative Literature and English and Bioethics Program, Faculty of the Liberal Arts, Pennsylvania State University, USA
}

Corresponding author: N Mngoma (mngoman@yahoo.com)

Background. Rates of gender-based violence (GBV) in South Africa (SA) are among the highest in the world. In societies where social ideals of masculinity encourage male dominance and control over women, gender power imbalances contribute to male perpetration and women's vulnerability. The drivers that cause men to perpetrate GBV and those that lead to HIV overlap and interact in multiple and complex ways. Multiple risk and protective factors for GBV perpetration by males operate interdependently at a number of levels; at the individual level, these include chronic anxiety and depression, which have been shown to lead to risky sexual behaviours.

Objectives. (i) To examine psychosocial risk factors (symptoms of anxiety and depression) as well as protective factors (social support and self-esteem) as self-reported by a cohort of males in rural KwaZulu-Natal (KZN) Province, SA; and (ii) to determine whether there are differences in anxiety, depression, social support and self-esteem between perpetrators and non-perpetrators.

Methods. A cross-sectional study using quasi-probability cluster sampling of 13 of 28 wards in Harry Gwala District, KZN. Participants were then randomly chosen from each ward proportionate to size.

Results. The participants were relatively young (median age 22 years); over half were schoolgoers, and $91.3 \%$ had never married. Over $43 \%$ of the sample reported clinical levels of anxiety and depressive symptoms on the Brief Symptom Inventory. Rates of GBV perpetration were $60.9 \%, 23.6 \%$ and $10.0 \%$ for psychological abuse, non-sexual physical violence and sexual violence, respectively. GBV perpetration was associated with higher depression, higher anxiety, lower self-esteem and lower social support.

Conclusions. Interventions to address GBV need to take modifiable individual-level factors into account.

S Afr Med J 2016;106(12):1211-1215. DOI:10.7196/SAMJ.2016.v106i12.11383

Rates of gender-based violence (GBV) in South Africa (SA) are among the highest in the world. ${ }^{[1]} \mathrm{GBV}$ is a term used to refer to any act that results or is likely to result in psychological, physical or sexual harm perpetrated against a person's will, and that is a result of gendered power inequalities. ${ }^{[2]}$ As such, the term includes, but is not limited to, intimate partner violence (IPV). Global estimates suggest that nearly one-third of women in a relationship will experience IPV at some point. ${ }^{[1]}$ In SA, GBV is a widespread and significant problem. ${ }^{[3]}$ A study conducted between 2010 and 2012 found that a significant proportion of women (77\% in Limpopo, $51 \%$ in Gauteng, $45 \%$ in the Western Cape and 36\% in KwaZulu-Natal (KZN) provinces) had experienced some form of GBV during their lifetime. ${ }^{[3]}$ In the same study, the proportions of men who reported perpetrating acts of violence against women ranged from $35 \%$ to $76 \%$ across the four provinces. ${ }^{[3]}$

The drivers that cause men to perpetrate GBV and those that lead to HIV overlap and interact in multiple and complex ways. ${ }^{[4]}$ In societies where social ideals of masculinity encourage male dominance and control over women, gender power imbalances contribute to male perpetration and women's vulnerability. ${ }^{[4]} \mathrm{GBV}$ or fear of it disempowers and subordinates women and can interfere with their ability to negotiate safer sex practices or refuse unwanted sex, and access and/or adhere to treatment and care, thus leaving them more vulnerable to HIV. ${ }^{[5]}$
Multiple and inter-related risk and protective factors for GBV perpetration by males operate interdependently at the level of the individual, the community and the wider society ${ }^{[4]}$ At the individual level, psychological distress, including chronic anxiety and depression, has been shown to lead to risky sexual behaviours, which further increase the risk of HIV transmission. ${ }^{[4]}$ Men who perpetrate GBV also tend to engage in more risky sex and to have multiple concurrent partners, and are more likely to test positive for sexually transmitted infections, including HIV. ${ }^{[6]}$

Recent views suggest that primary interventions to prevent sexual and gender violence need to address male depression, anxiety and other psychosomatic symptoms. ${ }^{[7]}$ Other studies have reported that men who commit acts of violence against their female partners score higher than the norm on depression and anxiety subscales. ${ }^{[8]}$ Shorey et al.$^{[9]}$ have suggested that male perpetrators with depression and associated irritability are at an increased risk of perpetrating GBV. A possible explanatory mechanism for the relationship between psychological distress and perpetration of GBV may be that mental health problems cause difficulties with emotion regulation, and some men may use GBV perpetration as a way to cope with their painful emotions. ${ }^{[9]}$

Self-esteem and social support have been found to be negatively associated with GBV. For example, research by Capaldi et al. ${ }^{[10]}$ has shown that social support may be protective against GBV 
perpetration by men, whereas the interaction of low self-esteem with other internalising factors such as depression may increase the risk of GBV perpetration. The relationships between GBV perpetration and depression, anxiety, self-esteem and social support in the SA context warrant further study.

\section{Objectives}

To: (i) examine psychosocial risk factors (symptoms of anxiety and depression) as well as protective factors (social support and selfesteem) as self-reported by a cohort of males in rural KZN; and (ii) determine whether there are differences in anxiety, depression, social support and self-esteem between perpetrators and nonperpetrators. We hypothesised that perpetrators would have statistically higher anxiety and depression, and lower self-esteem and social support, than non-perpetrators.

\section{Methods \\ Study design}

We conducted a cross-sectional study using quasi-probability cluster sampling, in which we randomly chose 13 of 28 wards from two of the five sub-municipalities in Harry Gwala (formerly Sisonke) District, KZN, and then randomly chose participants from each ward, roughly proportionate to size. We chose this design for practical reasons because we did not have access to a sampling frame that listed all individuals in the area, or even all dwelling units.

\section{Sample}

The study sample consisted of 450 participants, ranging in age from 14 to 67 years (median 22), who lived in Harry Gwala District. Participants were included if they were male and aged $\geq 14$ years.

\section{Study procedures \\ Ethics approval}

The General Research Ethics Board at Queen's University, Kingston, Ontario, Canada (ref. no. GENG-008-08) and the Biomedical Research Ethics Committee of the University of KwaZulu-Natal (ref. no. BF007/08) approved the study.

\section{Data collection}

The data were collected as part of a larger study of men and boys investigating GBV and HIV in rural KZN. Once potential participants were identified, informed consent was obtained before any data collection was initiated. The data were collected using an audio, computer-assisted self-interviewing (ACASI) ${ }^{[11]}$ system that included written and audio recordings of each question and responses in isiZulu. The ACASI system provides privacy and confidentiality and is designed to avoid much of the difficulty commonly experienced in securing full and frank responses on sensitive and intimate subjects when a respondent is one-on-one with an interviewer. ${ }^{[10]}$ Trained data collectors set up the laptop computers and gave instructions on their use, but left informants to complete the surveys alone. Tents were provided for privacy. Participants required 30 - 120 minutes to complete the survey.

\section{Measures}

Our instrument development involved consultations with experts on Zulu history, language and culture, a series of cognitive interviews with community members, and translation and back-translation of the survey. Respondents provided personal information on a wide variety of demographic characteristics including education, religious affiliation and socioeconomic status; psychosocial distress; parental and social support; self-esteem; gender relations, including violence and threats against women; and attitudes and practices in relation to sexual behaviour, including condom use and knowledge of HIV/ AIDS. We used a subset of these measures for the current analysis.

Demographic data. Basic demographic information was collected to describe the sample.

Brief Symptom Inventory (BSI). We assessed symptoms of psychosocial distress using the BSI, a 53-item self-report measure designed for use in non-patient and patient populations. ${ }^{[12]}$ The BSI has been used in SA previously, for example by Collings ${ }^{[13]}$ in a study of long-term effects of child sexual abuse in SA men of university age. The BSI has nine subscales or symptom dimensions. In the current study, we used two of the nine subscales, depression and anxiety. The following question is asked in relation to a list of specific psychosocial problems: 'How much has that problem distressed or bothered you during the past 7 days including today?' The response options range from 0 (has bothered me not at all) to 4 (has bothered me extremely). ${ }^{[12]}$ A $t$-score of $\geq 63$ on any BSI dimension indicates high psychosocial distress and a need for further psychological evaluation (caseness). The BSI has good psychometric properties, with reported test-retest reliability coefficients varying from 0.68 for the somatisation dimension to 0.91 for the phobic anxiety dimension, ${ }^{[12]}$ and good convergent construct validity with the Minnesota Multiphasic Personality Inventory, with correlations of 0.72 and 0.57 for the depression and anxiety subscales, respectively. ${ }^{[12]}$

Gender-based violence. We used a 32-item GBV scale to assess GBV. ${ }^{[14]}$ For each item, we asked participants to report how many times in the previous year they had engaged in the act against a girlfriend, wife or other female, with response options of never, once, a few times, and many times. We grouped the items or acts into three categories: psychological abuse, non-sexual physical violence, and sexual violence. From the responses, and for each category, we categorised the participants into perpetrators (those who reported committing any of the acts in a category at least once) and nonperpetrators (those who reported never committing any acts in a category). Participants who did not report committing an act, and refused to answer one or more of the items in a category, were assigned to the 'refused to answer' group.

The 'psychological abuse' subscale comprised 16 items, including insulting or swearing, throwing or breaking an object, and threatening to hurt. The 'non-sexual physical violence' subscale had 12 items, ranging from pushing or shoving to shooting. Finally, the 'sexual violence' subscale was made up of four items: demanding sex when the female did not want it, making her have oral sex against her will, physically forcing her to have sex, and forcing an object into her vagina against her will.

Rosenberg Self-esteem Scale (RSE). The RSE ${ }^{[15]}$ is a widely used 10 -item self-esteem measure. It has high test-retest reliability, with correlations typically in the range of $0.82-0.88$, and Cronbach's alpha values for various samples in the range of $0.77-0.88 .{ }^{[15]}$ Response options are strongly agree (4), agree (3), disagree (2) and strongly disagree (1). After reverse-coding appropriate items, the scale ranges from 10 to 40 , with 40 indicating the highest score possible. Higher scores reflect higher self-esteem.

Social Provisions Scale (SPS). To measure the degree of perceived social support we used the SPS, ${ }^{[16]}$ which asks participants to consider their current relationships with family, friends, co-workers, community members and others, and answer to what extent they agree with each of the 24 statements. The response options are strongly disagree (1), disagree (2), agree (3) and strongly agree (4), such that the higher the score, the higher the degree of social support. 
The SPS assesses a range of dimensions of perceived social support, including guidance (receiving advice and/or information), reliable alliance (feeling assured that one can rely on others for concrete assistance, if needed), reassurance of worth (feeling important to or valued by others), opportunity for nurturance (feeling needed to provide nurturing attention to others), attachments (receiving a sense of emotional security from close relationships), and social integration (a sense of belonging in a group that includes others with similar interests, values or ideas). The scale ranges from 24 to 96 . The SPS has good psychometric properties, with Cronbach's alpha values of $0.85,0.87$ and 0.82 for all subjects, males and females, respectively. ${ }^{[16]}$

\section{Data analysis}

The data were analysed using SPSS version 22.0 (IBM, USA). We first used descriptive statistics to determine sample characteristics and distribution of the measures. We then used hand scoring to convert the raw BSI dimension scores into standardised $(t-)$ scores, which we then used to determine 'caseness'. A $t$-score of $\geq 63$ on any BSI dimension indicates high psychosocial distress meeting a clinical definition. ${ }^{[12]}$

Finally, we used multivariate analysis of variance (MANOVA) to determine relationships between the four psychosocial covariates (anxiety, depression, self-esteem and social support) and GBV perpetration.

Table 1. Demographic data for the survey respondents

\begin{tabular}{ll}
\hline Variable & $\boldsymbol{n}(\%)$ \\
\hline $\begin{array}{l}\text { Marital status } \\
\text { Never married, long-term }\end{array}$ & $192(42.7)$ \\
partner & \\
Never married, no long- & $218(48.4)$ \\
term partner & \\
Married, one partner & $39(8.7)$ \\
Married, multiple & $1(0.2)$ \\
partners & \\
$\begin{array}{l}\text { Highest education level } \\
\text { attained }\end{array}$ & \\
$<$ Grade 9 & $135(30.0)$ \\
Grades 9 - 11 & $207(46.0)$ \\
Secondary school & $94(20.9)$ \\
Post-secondary & $14(3.1)$ \\
Employment status & \\
Employed (full time) & $26(5.8)$ \\
Employed (part time) & $22(4.9)$ \\
Unemployed & $147(32.8)$ \\
Student & $253(56.5)$ \\
*Two participants reported volunteering full time and \\
were dropped from the analyses that included the \\
employment measure.
\end{tabular}

\section{Results}

\section{Characteristics of the sample}

The participants were aged $14-67$ years (median 22). Most (91.3\%) had never married, although $42.7 \%$ of them had a long-term partner and one man had multiple wives. In terms of levels of education, 30.0\% had attained less than Grade 9, and 46.0\% had completed Grades 9 - 11. Twenty-one percent had completed high school, but only $3.1 \%$ had any post-secondary training (Table 1). More than half $(56.5 \%)$ were school students, $32.8 \%$ were unemployed, $5.8 \%$ were working full time, and $4.9 \%$ worked part time (Table 1).

\section{Gender-based violence}

We categorised participants into perpetrator (v. non-perpetrator) if they reported committing one or more acts of abuse or violence. When we considered each category of GBV separately, psychological abuse perpetration was reported by relatively more participants (60.9\%) than either non-sexual physical violence $(23.6 \%)$ or sexual violence (10.0\%) (Table 2).

\section{Anxiety, depression, self-esteem and social support}

Using the clinical definition of caseness ( $t$-score $\geq 63$ ), $42.7 \%$ and $44.5 \%$ of partici-

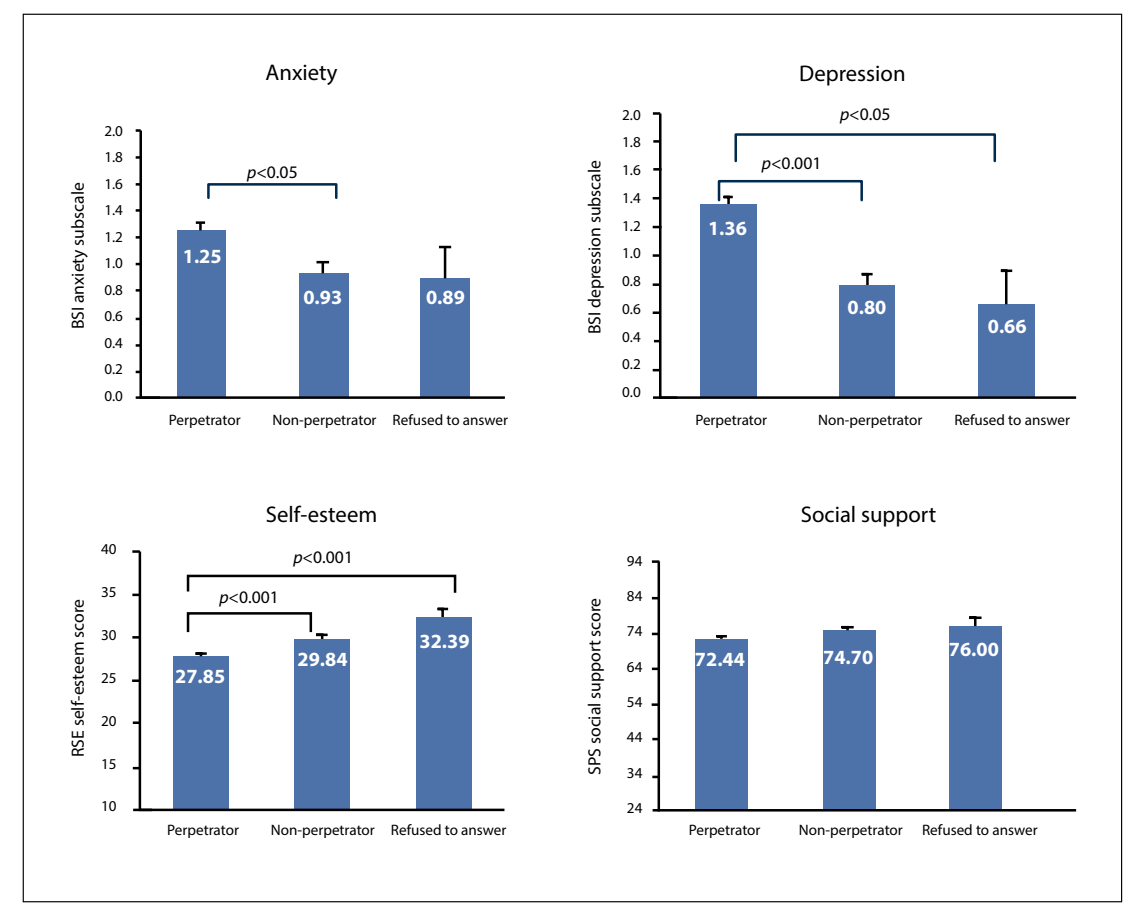

Fig. 1. Psychological abuse perpetration: mean scoresfor anxiety, depression, self-esteem and social support.

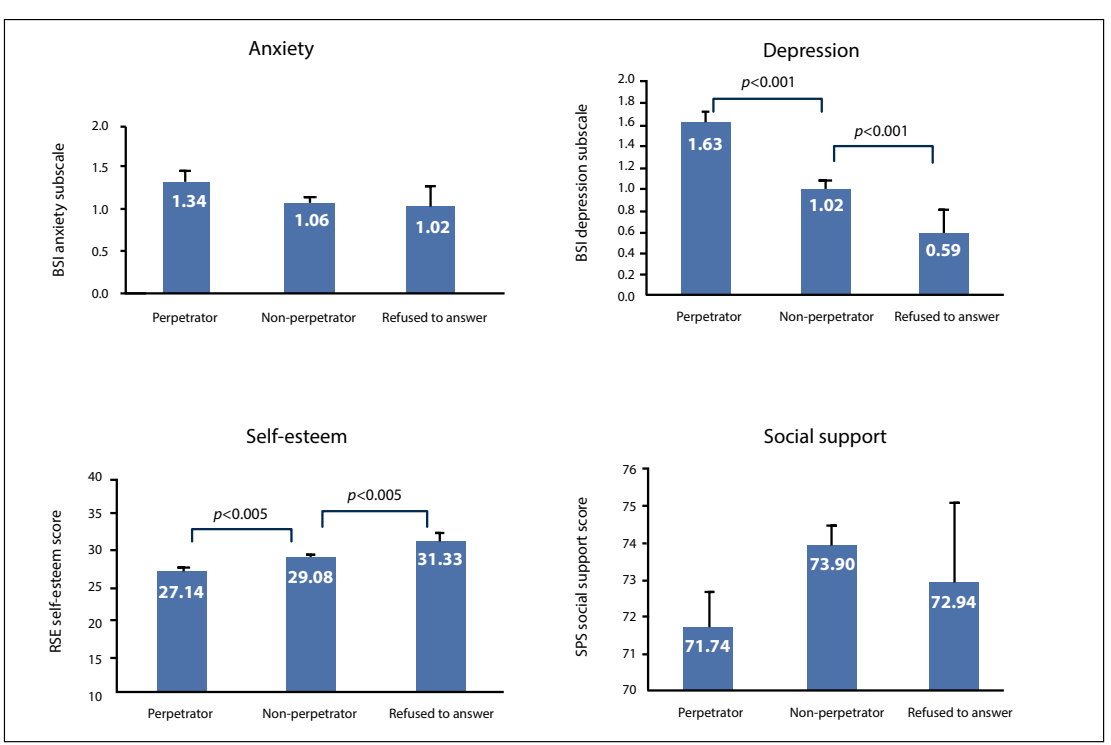

Fig. 2. Non-sexual physical violence perpetration: mean scores for anxiety, depression, self-esteem and social support. 
Table 2. Respondents who reported perpetrating or not perpetrating acts of GBV

\begin{tabular}{lllll}
\hline & $\begin{array}{l}\text { Perpetrator, } \\
\boldsymbol{n}(\%)\end{array}$ & $\begin{array}{l}\text { Non-perpetrator, } \\
\boldsymbol{n}(\%)\end{array}$ & $\begin{array}{l}\text { Refused to answer, } \\
\boldsymbol{n}(\%)\end{array}$ & $\begin{array}{l}\text { Total, } \\
\boldsymbol{N}(\%)\end{array}$ \\
\hline Psychological abuse & $274(60.9)$ & $149(33.1)$ & $27(6.0)$ & $450(100)$ \\
Non-sexual physical violence & $106(23.6)$ & $317(70.4)$ & $27(6.0)$ & $450(100)$ \\
Sexual violence & $45(10.0)$ & $380(84.4)$ & $25(5.6)$ & $450(100)$
\end{tabular}

Table 3. Proportion of participants with anxiety and depression

\begin{tabular}{llll}
\hline & High, $\boldsymbol{n}(\%)$ & Low, $\boldsymbol{n}(\%)$ & Total, $\boldsymbol{N}(\%)$ \\
\hline Anxiety & $185(42.7)$ & $248(57.3)$ & $433(100)$ \\
Depression & $196(44.5)$ & $244(55.5)$ & $440(100)$
\end{tabular}

pants had scores indicative of anxiety and depression, respectively (Table 3).

More than half of the sample did not meet the clinical cut-offs for anxiety (57.3\%) and depression (55.5\%). Raw scores for the BSI anxiety and depression subscales ranged from 0.00 to 4.00, as detailed in Table 4 .

Scores for the RSE scale ranged from 15 to 40 out of a possible maximum score of 40 , with higher scores reflecting higher self-esteem. The mean score for the SPS was 73.30 (SD 9.27) indicating a moderately high level of social support (Table 4).

\section{MANOVA}

\section{Psychological abuse perpetration}

Wilks' lambda showed that there were significant differences between perpetration categories on the psychological correlates $\left(\Lambda=0.900, \mathrm{~F}_{(8,800)}=5.43, p<0.001\right)$. Followup univariate ANOVAs showed differences between perpetration categories on anxiety $\left(\mathrm{F}_{(2,403)}=4.65, p=0.010\right)$, depression $\left(\mathrm{F}_{(2,403)}=15.75, p<0.001\right)$, self-esteem $\left(\mathrm{F}_{(2,403)}=13.56, p<0.001\right)$ and social support $\left(\mathrm{F}_{(2,403)}=3.51, p=0.031\right)$. Fig. 1 shows the mean scores on the psychosocial correlates for each category of perpetration (perpetrator, non-perpetrator and refused to answer), and indicates where those scores are significantly different from one another.

\section{Non-sexual physical violence perpetration}

Wilks' lambda showed that there were significant differences between perpetration categories on the psychological correlates $\left(\Lambda=0.903, \mathrm{~F}_{(8,800)}=5.22, p<0.001\right)$. Follow-up univariate analysis of variance (ANOVA) showed differences between perpetration categories on depression $\left(\mathrm{F}_{(2,403)}=15.96\right.$, $p<0.001)$ and self-esteem $\left(\mathrm{F}_{(2,403)}=8.83\right.$, $p<0.001)$, but not for anxiety $\left(\mathrm{F}_{(2,403)}=2.62\right.$, $p=0.074)$ or social support $\left(\mathrm{F}_{(2,403)}=2.05\right.$, $p=0.130)$. Fig. 2 shows the mean scores on the psychosocial correlates for each category of perpetration, and indicates where those scores are significantly different from one another.

\section{Sexual violence perpetration}

Wilks' lambda showed that there were significant differences between perpetration categories on the psychological correlates $\left(\Lambda=0.956, \mathrm{~F}_{(8,800)}=2.26, p<0.001\right)$. Followup univariate ANOVAs showed differences between perpetration categories on depression $\left(\mathrm{F}_{(2,403)}=4.34, \quad p<0.05\right)$, self-esteem $\left(\mathrm{F}_{(2,403)}=5.02, p<0.05\right)$ and social support $\left(\mathrm{F}_{(2,403)}=3.32, p=0.05\right)$, but not anxiety $\left(\mathrm{F}_{(2,403)}=1.24, p=0.291\right)$. Fig. 3 shows the mean scores on the psychosocial correlates for each category of perpetration, and indicates where those scores are significantly different from one another.

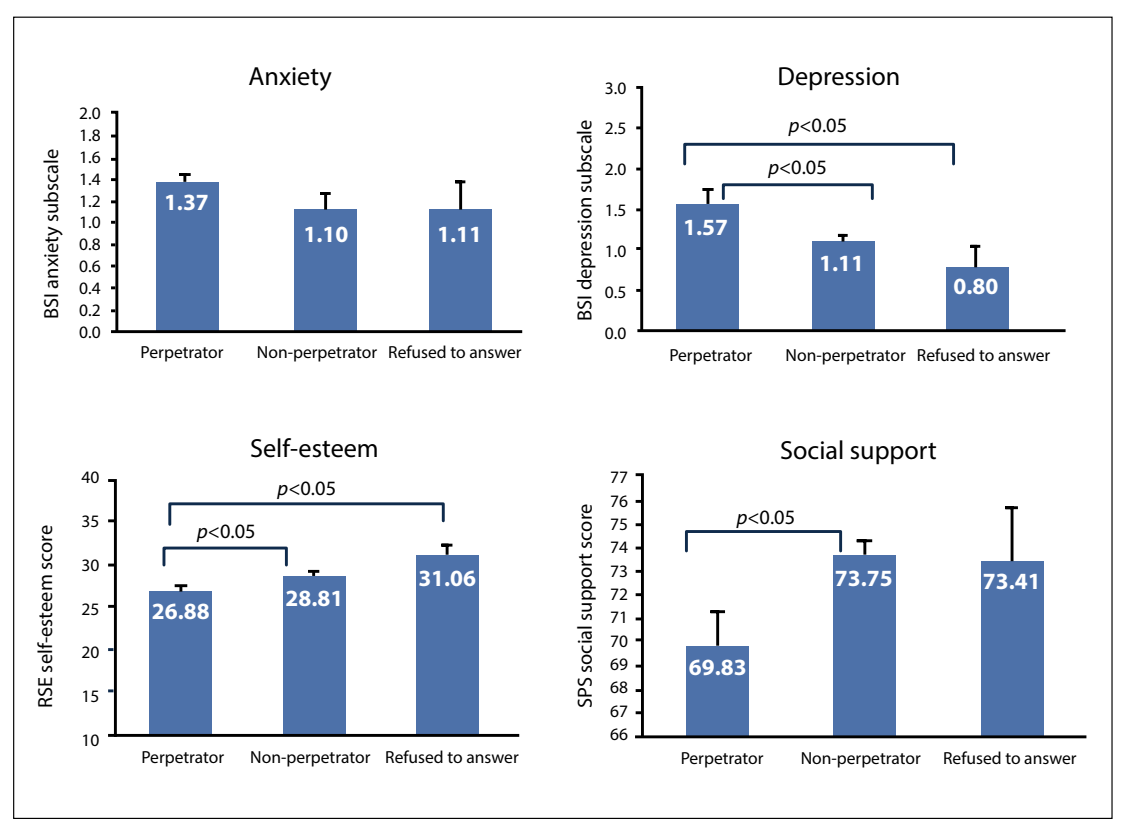

Fig. 3. Sexual violence perpetration: mean scores for anxiety, depression, self-esteem and social support.

Table 4. Raw scores for anxiety, depression, self-esteem and social provisions

\begin{tabular}{lllll}
\hline & $\boldsymbol{n}$ & Mean (SD) & $\begin{array}{l}\text { Minimum } \\
\text { score }\end{array}$ & $\begin{array}{l}\text { Maximum } \\
\text { score }\end{array}$ \\
\hline BSI: anxiety subscale & 433 & $1.13(1.02)$ & 0.00 & 4.00 \\
BSI: depression subscale & 440 & $1.14(1.03)$ & 0.00 & 4.00 \\
RSE & 436 & $28.70(4.90)$ & 15 & 40 \\
SPS & 422 & $73.30(9.27)$ & 48 & 95
\end{tabular}


intimate partner. ${ }^{[17]}$ Sixty percent of the males in our young sample had been involved in psychological abuse of a female. In contrast to previous studies, we found higher rates of psychological distress and GBV, particularly striking given the young age of the participants.

A notable finding was that a number of participants refused to answer questions on GBV perpetration. Although we do not know why some people refused to answer, it is possible that they were uncomfortable admitting perpetration, or were non-perpetrators and uncomfortable discussing violence perpetration. When we compared this group with perpetrators and non-perpetrators, the results were mixed in that they differed significantly from perpetrators in some instances, and yet in others did not. These findings need to be further explored in future research.

Social support appeared to be significantly protective only against sexual abuse perpetration in this study. This could be because levels of social support were fairly high among all groups. Social isolation has been linked to sexual violence perpetration in other studies.

One possible explanation for instances where our results did not reach statistical significance involves the timing of the questions. Our reference timeframe for risk/protective factors was the past 2 weeks, and for perpetration it was the past year. It is possible that better congruence between time frames, or even a longitudinal study, would have strengthened our pattern of results.

\section{Study limitations}

Limitations to the study include the cross-sectional nature of the design and the type of sampling strategy we used; for practical reasons, these were the best options available to us at the time. Another limitation is that the survey included questions of a deeply personal nature, asking about sexual practices and perpetration of GBV. Social desirability bias therefore cannot be ruled out. However, the data were collected using the ACASI system, which provides privacy and confidentiality and is designed to avoid much of the difficulty commonly experienced in securing full and frank responses on sensitive and intimate subjects when a respondent is one-on-one with an interviewer.

\section{Conclusions}

Our results have implications for those intervening in the area of GBV in rural areas of SA. Beyond addressing structural drivers of GBV, it is important to screen, identify and address those psychological risk factors that predispose individuals to perpetrate acts of gender violence, and to enhance the protective factors. For example, Gevers and Dartnell ${ }^{[7]}$ propose that GBV prevention interventions should include addressing individual factors that are likely to be protective against GBV perpetration.

1. Devries KM, Mak JY, Garcia-Moreno C, et al. Global health: The global prevalence of intimate partner violence against women. Science 2013;340(6140):1527-1528. http://dx.doi.org/10.1126/science. 1240937 Reproductive Health Response in Conflict (RHRC) Consortium. Gender-Based Violence Tools Manual New York: RHRC Consortium, 2014.

South Africa Info. Study reveals extent of gender violence. http://www.southafrica.info/services/rights South Africa Info. Study reveals extent of gender violence. htt
gender-051212.htm\#.V3BzQpMrLUo (accessed 7 June 2016).

gender-051212.htm\#.V3BzQpMrLUo (accessed 7 June 2016).
Jewkes R, Dunkle K, Nduna M, Shai N. Intimate partner violence, relationship power inequity, and

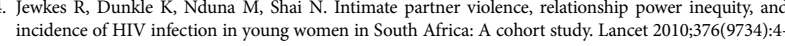
48. http://dx.doi.org/10.1016/S0140-6736(10)60548-X

5. Campbell JC, Baty ML, Ghandour RM, et al. The intersection of intimate partner violence agains women and HIV/AIDS: A review. Int J Inj Contr Saf Promot 2008;15(4):221-231. http://dx.doi. org/10.1080/17457300802423224

6. Dunkle KL, Decker MR. Gender-based violence and HIV: Reviewing the evidence for links and causa pathways in the general population and high-risk groups. Am J Reprod Immunol 2013;69(Suppl 1):2026. http://dx.doi.org/10.1111/aji.12039

7. Gevers AK, Dartnell E. The role of mental health in primary prevention of sexual and gender-based violence. Glob Health Action 2014;7:24741. http://dx.doi.org/10.3402/gha.v7.24741

8. Barrera M, Palmer S, Brown R, et al. Characteristics of court-involved men who abuse their wives. J Fam Violence 1994;9(4):333-345. http://dx.doi.org/10.1007/BF01531943

Shorey RC, Febres J, Brasfield H, et al. The prevalence of mental health problems in men arrested for domestic violence. J Fam Violence 2012;27(8):741-748. http://dx.doi.org/10.1007/s10896-012-9463-z

10. Capaldi DM, Knoble NB, Shortt JW, et al. A systematic review of risk factors for intimate partner violence. Partner Abuse 2012;3(2):231-280. http://dx.doi.org/10.1891/1946-6560.3.2.231

1. Jewkes R, Sikweyiya Y, Morrell R, Dunkle K. Understanding Men's Health and Use of Violence. Pretoria: South African Medical Research Council, 2009.

12. Derogatis LR. BSI Brief Symptom Inventory. Administration, Scoring, and Procedures Manual. 4th ed. Minneapolis, Minn.: National Computer Systems, 1993.

13. Collings SJ. The long-term effects of contact and noncontact forms of child sexual abuse in a sample of university men. Child Abuse Negl 1997;19(1):1-6. http://dx.doi.org/10.1016/0145-2134(94)00098-F Marshall L. Development of the severity of violence against women scales. J Fam Violence 1992;7(2):103121. http://dx.doi.org/10.1007/BF00978700

15. Blascovich J, Tomaka J. Measures of self-esteem. In: Robinson JP, Shaver PR, Wrightsman LS, eds. Measures of Personality and Social Psychological Attitudes. 3rd ed. Ann Arbor, Mich.: Institute for Social Measures of Personality and Social Psychological Attitudes. 3rd ed. Ann Arbor, Mich.: Institute for Socia
Research, 1993:115-160.

6. Cutrona CE, Russell D. The provisions of social relationships and adaptation to stress. In: Jones WH, Perlman D, eds. Advances in Personal Relationships. Greenwich, Conn.: JAI Press, 1987:37-67.

7. Jewkes R, Dunkle K, Koss M, et al. Rape perpetration by young, rural South African men Prevalence, patterns and risk factors. Soc Sci Med 2006;63(11):2949-2961. http://dx.doi.org/10.1016 j.socscimed.2006.07.027

Accepted 14 September 2016. 